\title{
Transplant Tourism and Organ Trafficking: Current Practices, Controversies and Solutions
}

\author{
Gerard Thomas Flaherty ${ }^{1,2 *} \mathbb{}$, Nizrull Nasir ${ }^{3}$, Conor M. Gormley ${ }^{4}$, Suyash Pandey ${ }^{1}$ \\ ${ }^{1}$ School of Medicine, National University of Ireland, Galway, Ireland \\ ${ }^{2}$ School of Medicine, International Medical University, Kuala Lumpur, Malaysia \\ ${ }^{3}$ School of Medicine and Medical Science, University College Dublin, Dublin, Ireland \\ ${ }^{4}$ Department of Medicine, Joondalup Hospital, Perth, Australia
}

Corresponding Author: Gerard Thomas Flaherty, MD, Professor, School of Medicine, National University of Ireland Galway, Ireland. Tel: +353-91495469, Email: gerard.flaherty@nuigalway.ie

Received January 15, 2021; Accepted May 10, 2021; Online Published June 26, 2021

\begin{abstract}
The controversial subject of transplant tourism has been neglected in the travel medicine literature. According to the Declaration of Istanbul, travel for transplantation can be regarded as transplant tourism if it involves organ trafficking and/or commercialised transplantation activities. While no registry of transplant tourism activities exists, published case series point to significant negative clinical outcomes. Adverse outcomes among donors include postoperative depression and anxiety, deterioration in health status, poor surgical wound care, and negative financial effects. Poor perioperative management, inadequate immunosuppression, blood transfusion-associated infections, antibiotic-resistant bacterial infections and invasive fungal infections, are among the most commonly reported complications in transplanted patients. Iran operates a legal and ethically regulated system of rewarded altruistic kidney donation. Travel medicine practitioners have a role to play in protecting the health of intending transplant tourists through targeted pre-travel health counselling and vaccination.
\end{abstract}

Keywords: Transplantation, Travel, Renal Transplant, Medical Tourism

Citation: Flaherty GT, Nasir N, Gormley CM, Pandey S. Transplant tourism and organ trafficking: current practices, controversies and solutions. Int J Travel Med Glob Health. 2021;9(3):102-106. doi:10.34172/ijtmgh.2021.17.

\section{Introduction}

Medical tourism, or travel across international borders for the purpose of receiving medical care either unavailable or inaccessible in the traveller's own country, has emerged as a burgeoning industry, projected to be worth an estimated $\$ 28$ billion per year by $2025 .{ }^{1}$ While the medical tourism categories of cardiac surgery tourism, ${ }^{2}$ cosmetic surgery tourism, ${ }^{3}$ and stem cell tourism ${ }^{4}$ have attracted the interest of travel medicine researchers, the more controversial subject of transplant tourism has been largely neglected in the travel medicine literature. One of the fundamental tenets of responsible international travel is to avoid causing harm to local people or fellow travellers. ${ }^{5}$ Aspects of transplant tourism challenge this ideal. Unlike medical tourism in general, transplant tourism has always generated controversy around the source of organs, post-transplant care of donors and the clinical outcomes in organ recipients. Living unrelated donor transplantation is vulnerable to unethical donor recruitment through coercion, corruption and commercialisation. The aim of this perspective article is to provide an overview of the current state of transplant tourism, to consider its origins, outcomes and ethical dilemmas, and to briefly examine sustainable models of transplant tourism which may better serve the interests of society.

\section{Defining Transplant Tourism}

Transplant tourism involves travel outside one's country of residence, with the aim of procuring organ, predominantly kidney, liver or corneal, transplantation services. Legal transplant tourism may legitimately involve emotionally or biologically related individuals, one or both of whom have crossed international borders to receive an organ transplant in a country with developed or more accessible transplantation services. Some neighbouring countries, such as the Republic of Ireland and the United Kingdom, operate official bilateral organ sharing programs. Such cooperative agreements are not considered to constitute transplant tourism. According to the 2008 Declaration of Istanbul, which has been recently updated, ${ }^{6}$ travel for transplantation can be regarded as a form of transplant tourism if it involves organ trafficking and/or commercialised transplantation activities, or if the country's capacity to fulfil its own citizens' transplant requirements is

Copyright $\odot 2021$ The Author(s). This is an open-access article distributed under the terms of the Creative Commons Attribution License (http:// creativecommons.org/licenses/by/4.0), which permits unrestricted use, distribution, and reproduction in any medium, provided the original work is properly cited. 
undermined as a result. Models of transplant tourism include travel of either the donor or recipient to the other person's country, or movement of both donor and recipient from the same or two different countries to a transplant centre based in another country. ${ }^{7}$

\section{Drivers of Transplant Tourism}

Underlying factors which drive transplant tourism include the global increase in end-stage chronic kidney disease, secondary to ageing, diabetes and hypertension, with an excessive demand for a limited supply of donor kidneys. Patients may seek compatible organs outside their own national jurisdiction arising from personal suspension from transplant waiting lists for medical reasons, or because of a fear of dying on a waiting list. Many developing countries have poor dialysis facilities and limited deceased donor programs and surgical transplantation services. Cultural barriers existing in some countries serve to discourage altruistic organ donation, even between biological relatives. Widening wealth inequality has helped to sustain an underground market in transplant tourism, which has been perpetuated by difficulties in enforcing international laws. The insurance industry has also been criticised for incentivising patient travel for transplantation as a more cost-efficient alternative to providing prolonged dialysis on transplant waiting lists. ${ }^{8}$

\section{Demographics of Transplant Tourists}

It is estimated that up to 7000 ( $10 \%$ of total) kidney transplant procedures performed globally each year involve transplant tourists. ${ }^{9}$ Commercial services are typically advertised on websites and involve both single and combination organ packages. The transplant tourism cast includes underworld, so-called kidney hunters, medical tourism bureaus based in large western cities, organ brokers and outlaw surgeons, although the latter may be deceived by illegitimate claims of biological relationships between donors and recipients. Popular destinations for transplant tourism include countries in Asia (India, Pakistan, China, Philippines), Egypt, Moldova and Colombia. The typical profile of a transplant donor is that of a male in his late 1920s from a developing country in Asia or South America, with a meagre annual income. Organ recipients tend to be middle-aged males, native to developed economies in North America, Japan, Australia, Japan or Saudi Arabia, with a high financial net worth. A cross-sectional survey based on the experiences of nephrologists practising in the British Isles reported that almost two-thirds of renal consultants had cared for at least one patient who had travelled abroad for a kidney transplant, while less than half of the physician cohort had been informed by their patients prior to their overseas transplant tourism travel..$^{10}$ The study highlighted the suboptimal post-transplant prophylaxis received by the majority of patients.

\section{Patterns of Transplant Tourism}

A survey of kidney vendors in Pakistan found that over 2000 organs were sold there annually, two-thirds of which were transplanted to foreign tourists. ${ }^{11}$ The mean age of organ donors was 34 years and most were illiterate, bonded labourers with a mean monthly income of approximately \$US15. Over three quarters were in debt and this was the principal motivation for their decision to sell one of their kidneys. The average amount received by donors was \$US1377, which was $\$$ US 400 less than the amount pledged. While all donors were in good health prior to the transplant, just over 1\% reported good health following their surgery. Only $4 \%$ of donors managed to pay off their debts as a result of the transaction. A growing organ trade exists in neighbouring Bangladesh, where vendors are often recruited by misleading newspaper advertisements seeking the "noble act" of kidney donation. ${ }^{12}$ Assurances to cover all travel and healthcare expenses and to provide fair compensation do not materialise following the deduction of numerous hidden expenses. This form of bioviolence has led to the use of the term "living cadavers" to describe organ vendors in Bangladesh. In many cases, organ brokers provide counterfeit passports, which are then seized from donors after crossing the border into India, a popular host country for Bangladeshi organ vendors. Accommodation is often of a substandard nature, surgical scars are unnecessarily extensive and hospital discharge premature for organ donors, many of whom suffer long-term complications which impair their ability to perform manual work and provide for their family. Similar findings have been reported from a study of organ vendors in India, where a 1994 law prohibits the sale of kidneys. ${ }^{13}$ Controversy has long surrounded the Chinese practice of transplant tourism involving the use of prisoners as involuntary donors. Huang and colleagues reported that about two-thirds of organ transplants carried out in China involved the use of organs from deceased donors, more than $90 \%$ of whom were executed prisoners. ${ }^{14}$ The adoption by China in 2007 of the Human Transplantation Act banning commercialisation of organ transplants reduced the volume of transplants provided to foreign patients by $50 \%$ in 2007 and has been broadly welcomed by the international medical community. ${ }^{15}$

\section{Outcomes of Transplant Tourism Procedures}

While no reliable registry of transplant tourism activities exists, published case reports and case series provide insights into some of the adverse clinical outcomes affecting transplant donors and recipients. Transplant recipients may receive inadequate operative reports, written in an unfamiliar language to their own. Surgical complications, such as postoperative haemorrhage, pulmonary embolism, and wound infection or dehiscence, may arise which may be difficult to manage if premature hospital discharge occurs. Acute organ rejection may be secondary to inadequate immunosuppressant therapy. Invasive fungal infections, HIV, hepatitis B and C are among the many infectious risks which may occur in this setting. Adverse outcomes among donors include postoperative depression and anxiety, general deterioration in health status, poor surgical wound care, loss of employment, and negative financial effects.

Data relating to the outcomes of organ transplant procedures in the unregulated environment of transplant 
tourism are unreliable since recipients typically obtain follow-up care in their home countries and their transplant providers may be reluctant to publish adverse clinical data. It is generally accepted that outcomes in transplant tourists are inferior to those performed in ethical and regulated clinical settings. ${ }^{9}$ Poor perioperative management, inadequate immunosuppression, unsafe blood transfusion practices and a high incidence of invasive fungal infections, such as aspergillosis, are among the most commonly reported complications in transplant tourists. Table 1 summarises key outcomes of transplant tourist recipients in case series published within the last 5 years.

\section{Ethical Aspects of Transplant Tourism}

Transplant tourism raises several bioethical issues, ${ }^{21}$ including the exploitation of people living in poverty, coercion in relation to the provision of donor informed consent to nephrectomy, and inadequate follow-up medical care for donors. Transplant tourism allows patients with the financial means to bypass waiting lists for transplantation, thus further widening socioeconomic disparities in access to transplantation services. Commodification of the human body also raises profound ethical concerns. Provision of transplant tourism services may serve to undermine domestic transplantation activities. The burden placed on the returned tourist's own country's healthcare system when infectious complications arise because of suboptimal antimicrobial prophylaxis, or graft rejection because of inadequate immunosuppressant regimens, should also be considered. Notwithstanding these issues, physicians in the transplant tourist's country of origin are ethically obligated to provide quality long-term posttransplant care to these patients and manage complications according to local standards. The absence of regulation, of accountability, and of accreditation of transplant tourism services are additional causes of legitimate ethical concern. These ethical dilemmas must be interpreted in the light of a growing global demand for kidney transplants by patients suffering with end-stage renal disease.

\section{Regulation of Transplant Tourism}

Suggested measures to counter transplant tourism include legal enforcement in destination countries, extraterritorial criminalisation of recipients who travel overseas to receive an organ obtained through commercial means, self-policing of medical professionals involved in surgical transplant procedures, and restriction of insurance coverage in recipient countries. ${ }^{22}$ Improved management of modifiable risk factors for chronic kidney (e.g. hypertension and diabetes) and liver (e.g. alcohol abuse) disease will reduce the burden of demand on existing transplantation services. De novo stem cell regeneration of kidneys ${ }^{23}$ and three-dimensional bioprinting of organs ${ }^{24}$ offer futuristic solutions to the problem of inadequate donated organ supplies. Some argue that a regulated international market in organs from living donors would help to eliminate current underworld practices, provide transparency, and ensure that donors and recipients have access to high standards of medical care. ${ }^{9}$ Iran, a destination of growing importance in the medical tourism industry, ${ }^{25}$ is often held up as an exemplar for its introduction of a sustainable and ethical model of kidney donation which is available to its own citizens. ${ }^{26}$ According to this model, the Iranian government pays for all the hospital expenses associated with renal transplants. Essential immunosuppressive drugs are provided, thus improving the survival of grafted organs. Living unrelated donors receive a modest financial award for their altruism and are given access to free medical insurance for a year following the procedure. Strict ethical oversight is provided by the participating transplant teams and by the Iranian Society for Organ Transplantation. Such a model may achieve wider global acceptance as it places the poor and rich on an equal footing, removes the financially motivated involvement of middlemen, and safeguards patient safety by ensuring compliance with accepted medical standards of care.

\section{Travel Medicine and Transplant Tourism}

Travel medicine practitioners have a role to play in protecting the health of intending transplant tourists through pretravel health counselling and vaccination against nosocomial infectious diseases such as hepatitis B. ${ }^{27}$ Currently, no data exist on the numbers of commercial transplant tourists who attend for pre-travel health consultation. It is plausible that the majority of these travellers do not wish to disclose the real motivation for their travel, especially if the travel medicine provider is not their primary care physician. We recommend

Table 1. Characteristics and Outcomes of Transplant Tourists Undergoing Living Unrelated Renal Transplantation

\begin{tabular}{|c|c|c|c|}
\hline Study, country & $n$ & $\begin{array}{l}\text { Patient Survival (\%) } \\
\text { 1-Year, 5-Year }\end{array}$ & Comments \\
\hline $\begin{array}{l}\text { Tsai et al, }{ }^{16} \\
\text { Taiwan }\end{array}$ & 2518 & $95.8,87.8$ & $\begin{array}{l}\text { Overseas kidney transplant recipients were older, predominantly male, on dialysis for } \\
\text { shorter period, and with more comorbidities }\end{array}$ \\
\hline $\begin{array}{l}\text { Al Rahbi et al, }{ }^{17} \\
\text { Oman }\end{array}$ & 106 & Not reported & $\begin{array}{l}60 \% \text { were male, with average age of } 41.5 \text { years; } 13 \% \text { objected to receiving an organ } \\
\text { from a family member }\end{array}$ \\
\hline $\begin{array}{l}\text { Amira et al, }{ }^{18} \\
\text { Nigeria }\end{array}$ & 26 & $84.6,41.7$ & $\begin{array}{l}73 \% \text { were male, with mean age } 40.5 \text { years; majority of transplants performed in India; } \\
\text { infectious complications in } 42 \%\end{array}$ \\
\hline $\begin{array}{l}\text { Al Salmi et al, }{ }^{19} \\
\text { Oman }\end{array}$ & 162 & Not reported & Main destination was Pakistan; Aspergillus infections occurred in $8 \%$ of patients \\
\hline $\begin{array}{l}\text { Stewart et al, }{ }^{20} \\
\text { USA }\end{array}$ & 1 & Patient well at 4 months & $\begin{array}{l}\text { Case study of } 61 \text {-year old Pakistani-American male who travelled to Pakistan for a kidney } \\
\text { transplant; complicated by life-threatening necrotising kidney allograft infection }\end{array}$ \\
\hline
\end{tabular}


that information on transplant tourism be presented at travel medicine conferences and symposia. Travel medicine physicians should receive guidance on what transplantrelated information to seek in these settings and what specific surgical tourism advice to provide. It may also be appropriate in selected cases to deter patients from travelling for transplant tourism. ${ }^{28}$ They also need to be aware of their legal and bioethical obligations. Future research should examine the perspectives and experiences of active travel medicine physicians in relation to suspected or confirmed transplant tourists they have encountered in clinical practice.

\section{Conclusion}

International travel for the purpose of undergoing commercialised organ transplantation continues to be a controversial subject which is at odds with ethical principles of good medical practice. The underlying factors which facilitate transplant tourism are complex and have their origins in global wealth inequality and poorly developed organ donation and transplantation service in many countries. The Iranian model of regulated commercialisation of organ transplantation has been held up as a proposed solution to many of the problems caused by illegal, unregulated activities. The travel medicine community should be aware of the potential for transplant tourists to seek pre-travel healthcare. Travel medicine physicians should endeavour to protect transplant tourists from procedure-related infections as well as counsel them about the risks of obtaining an organ overseas from a living unrelated donor.

\section{Authors' Contributions}

GTF was responsible for study conception, literature review and preparation of the first draft of the manuscript. All other authors contributed equally to the literature search, manuscript planning and editing of the draft manuscript. All authors read and approved the final version of the manuscript.

\section{Conflict of Interest Disclosures}

The authors have no conflicts of interest to declare.

\section{Ethical Approval}

Not applicable.

\section{Funding/Support}

This research did not receive any specific grant from funding agencies in the public, commercial, or not-for-profit sectors.

\section{References}

1. Çapar H, Aslan Ö. Factors affecting destination choice in medical tourism. Int J Travel Med Glob Health. 2020;8(2):80-88. doi:10.34172/ijtmgh.2020.13

2. Noori F, Kargari M. Iran's medical tourism development model in cardiac surgery. Int J Travel Med Glob Health. 2016;4(2):5764. doi:10.20286/ijtmgh-04025

3. Pereira RT, Malone CM, Flaherty GT. Aesthetic journeys: a review of cosmetic surgery tourism. J Travel Med. 2018;25(1):tay042. doi:10.1093/jtm/tay042

4. Connolly R, O’Brien T, Flaherty G. Stem cell tourism--a webbased analysis of clinical services available to international travellers. Travel Med Infect Dis. 2014;12(6 Pt B):695-701. doi:10.1016/j.tmaid.2014.09.008

5. Lim BCW, Flaherty GT. Leaving light footprints-the importance of promoting responsible international travel. Int J Travel Med Glob Health. 2018;6(3):88-91. doi:10.15171/ijtmgh.2018.18

6. Pullen LC. Ten-year celebration of the Declaration of Istanbul: significant updates mark the 10th anniversary of the globally endorsed Declaration. Am J Transplant. 2018;18(11):26152616. doi:10.1111/ajt.15138

7. Shimazono Y. The state of the international organ trade: a provisional picture based on integration of available information. Bull World Health Organ. 2007;85(12):955-962. doi:10.2471/blt.06.039370

8. Bramstedt KA, Xu J. Checklist: passport, plane ticket, organ transplant. Am J Transplant. 2007;7(7):1698-1701. doi:10.1111/ j.1600-6143.2007.01847.x

9. Akoh JA. Key issues in transplant tourism. World J Transplant. 2012;2(1):9-18. doi:10.5500/wjt.v2.i1.9

10. Odedra A, Green ST, Bazaz R. United Kingdom and Republic of Ireland renal physicians' experiences of patients undergoing renal transplants abroad: a questionnaire-based cross-sectional survey. Travel Med Infect Dis. 2014;12(6 Pt B):702-706. doi:10.1016/j.tmaid.2014.04.002

11. Naqvi SA, Ali B, Mazhar F, Zafar MN, Rizvi SA. A socioeconomic survey of kidney vendors in Pakistan. Transpl Int. 2007;20(11):934-939. doi:10.1111/j.1432-2277.2007.00529.x

12. Moniruzzaman M. "Living cadavers" in Bangladesh: bioviolence in the human organ bazaar. Med Anthropol Q. 2012;26(1):6991. doi:10.1111/j.1548-1387.2011.01197.x

13. Goyal M, Mehta RL, Schneiderman LJ, Sehgal AR. Economic and health consequences of selling a kidney in India. JAMA. 2002;288(13):1589-1593. doi:10.1001/jama.288.13.1589

14. Huang J, Mao Y, Millis JM. Government policy and organ transplantation in China. Lancet. 2008;372(9654):1937-1938. doi:10.1016/s0140-6736(08)61359-8

15. The Lancet. Weaning China off organs from executed prisoners. Lancet. 2015;385(9962):1. doi:10.1016/s0140-6736(14)62462-4

16. Tsai DF, Huang SW, Holm S, Lin YP, Chang YK, Hsu CC. The outcomes and controversies of transplant tourism-lessons of an 11-year retrospective cohort study from Taiwan. PLoS One. 2017;12(6):e0178569. doi:10.1371/journal.pone.0178569

17. Al Salmi I, Metry AM, Al Ismaili F, et al. Transplant tourism and invasive fungal infection. Int J Infect Dis. 2018;69:120-129. doi:10.1016/j.ijid.2018.01.029

18. Al Rahbi F, Al Salmi I. Commercial kidney transplantation: attitude, knowledge, perception, and experience of recipients. Kidney Int Rep. 2017;2(4):626-633. doi:10.1016/j. ekir.2017.02.010

19. Amira CO, Bello BT. Do the benefits of transplant tourism amongst Nigerian patients outweigh the risks? a single-center experience. Int J Organ Transplant Med. 2017;8(3):132-139.

20. Stewart J, Snoeyenbos Newman G, Jain R, et al. Transplant tourism complicated by life-threatening New Delhi metallo- $\beta$ lactamase-1 infection. Am J Transplant. 2019;19(4):1224-1228. doi:10.1111/ajt.15136

21. Cohen IG. Transplant tourism: the ethics and regulation of international markets for organs. J Law Med Ethics. 2013;41(1):269-285. doi:10.1111/jlme.12018

22. Budiani-Saberi DA, Delmonico FL. Organ trafficking and transplant tourism: a commentary on the global realities. Am J Transplant. 2008;8(5):925-929. doi:10.1111/j.16006143.2008.02200.x

23. Yokote S, Yamanaka S, Yokoo T. De novo kidney regeneration 
with stem cells. J Biomed Biotechnol. 2012;2012:453519. doi:10.1155/2012/453519

24. Murphy SV, Atala A. 3D bioprinting of tissues and organs. Nat Biotechnol. 2014;32(8):773-785. doi:10.1038/nbt.2958

25. Gholami M, Keshtvarz Hesam Abadi AM, Miladi S, Gholami M. A systematic review of the factors affecting the growth of medical tourism in Iran. Int $J$ Travel Med Glob Health. 2020;8(1):1-12. doi:10.34172/ijtmgh.2020.01

26. Hamidian Jahromi A, Fry-Revere S, Bastani B. A revised
Iranian model of organ donation as an answer to the current organ shortage crisis. Iran J Kidney Dis. 2015;9(5):354-360.

27. Kotton CN, Hibberd PL. Travel medicine and transplant tourism in solid organ transplantation. Am J Transplant. 2013;13 Suppl 4:337-347. doi:10.1111/ajt.12125

28. Gill J, Diec O, Landsberg DN, et al. Opportunities to deter transplant tourism exist before referral for transplantation and during the workup and management of transplant candidates. Kidney Int. 2011;79(9):1026-1031. doi:10.1038/ki.2010.540 